\title{
Functional Polymer Blends and Nanocomposites
}

\author{
Christoph Weder ${ }^{\star}$
}

\begin{abstract}
The broad class of (multi)functional polymers with unusual combinations of optical, electronic, mechanical and other properties is attracting significant interest, because it conceptually combines the advantages of polymers - low cost, ease of processing and a range of attractive mechanical characteristics - with the specific, tailorable properties of functional organic molecules. The caveat is that the synthesis of functional polymers is frequently complex and involves many steps, which makes the technological exploitation of new materials difficult. One alternative strategy is the fabrication of functional polymer blends and nanocomposites. Rather than synthesizing new, complex functional macromolecules, minor fractions of a 'functional additive' are mixed with a matrix polymer in order to create, often after using rather specific processing protocols, new materials with unique or unusual property matrices. This review discusses three specific examples - chameleon polymers with integrated sensing capabilities, optically upconverting polymers, and mechanically adaptive nanocomposites - to showcase the conceptual simplicity, elegance, and broad applicability of this general design approach.
\end{abstract}

Keywords: Functional material $\cdot$ Nanocomposite $\cdot$ Polymer blend $\cdot$ Smart additive

Wyin Christoph Weder is Professor for Polymer Chemistry and Materials at the Adolphe Merkle Institute at the University of Fribourg and also the F. Alex Nason Professor in the Department of Macromolecular Science and Engineering at Case Western Reserve University in Cleveland OH (USA). Weder earned his academic degrees in chemistry (Dipl. Chem.) in 1990 and polymer science (Dr. sc. nat.) in 1994 at ETH Zürich, working under the direction of Professor Ueli Suter. He subsequently joined Mark Wrighton's group at MIT in Cambridge MA (USA) as a post-doctoral fellow, before returning to ETH Zürich in 1995, where the Materials Department appointed him first as senior assistant and lecturer, and after comple-

\footnotetext{
${ }^{*}$ Correspondence: Prof. Dr. C. Weder University of Fribourg

Adolphe Merkle Institute and Fribourg Center for Nanomaterials

Department of Polymer Chemistry and Materials $\mathrm{CH}-1723$ Marly, Switzerland

Tel.: +41263009465

Fax: +41263009624

E-mail: christoph.weder@unifr.ch

sprof. Weder is also the F. Alex Nason Professor of Engineering in the Department of Macromolecular Science and Engineering at Case Western Reserve University, Cleveland, $\mathrm{OH}$ 44106, USA
}

tion of his 'Habilitation', as independent lecturer. In 2001 Weder became professor at Case Western Reserve University, where he established the Functional Polymer Laboratory. In 2009, he moved his lab to the University of Fribourg. Weder's main research interests are the design, synthesis and investigation of structure-property relationship of novel functional polymer systems, in particular advanced materials with unusual optic or electronic properties, (semi)conducting conjugated polymers, stimuli-responsive polymers, biomimetic materials, and polymer nanocomposites.

\section{Introduction}

Motivated by academic curiosity and also by the significant potential for technological exploitation in countless applications that include, for example, security features, ${ }^{[1,2]}$ light-emitting diodes, ${ }^{[3,4]}$ lasers, ${ }^{[5]}$ chemical sensors, ${ }^{[6,7]}$ actuators, ${ }^{[8]}$ and many others, the development of (multi)functional polymers is attracting much interest in laboratories around the world. ${ }^{[9]}$ This broad class of 'advanced' materials with unusual combinations of optical, electronic, mechanical and other properties is attracting significant interest, because it conceptually combines the advantages of polymers - low cost, ease of processing and a range of attractive mechanical characteristics - with the specific, tailorable properties of functional organic molecules. The caveat is that the synthesis of functional polymers is frequently complex and involves many steps, which makes the technological exploitation of new materials unattractive. One alternative strategy is the fabrication of functional polymer blends and nanocomposites. Rather than synthesizing new, complex functional macromolecules, minor fractions of a 'functional additive' are mixed with a matrix polymer in order to create, often after using rather specific processing protocols, new materials with unique or unusual property matrices. Using three specific examples from our laboratory, this review seeks to showcase the conceptual simplicity, elegance, and broad applicability of this general design approach.

\section{Polymer Chameleons}

Förster and Kasper reported more than fifty years ago that a pair of identical fluorescent molecules could form an excimer, i.e. a complex between a molecule in an electronically excited state and a molecule of the same species in its ground state. ${ }^{[10]}$ The bound excimer has a lower potential energy than that of the separated components (i.e. a molecule in its first electronically excited state and a molecule in its ground state) and therefore excimers emit at higher wavelengths than the monomer ${ }^{[11]}$ species from which they are constituted. It has long been recognized that the formation of excimers in polymer hosts comprising a fluorescent probe can be used to extract structural information on the molecular (e.g. conformation and dynamics of macromolecules in solution ${ }^{[12]}$ ) as well as supramolecular level (e.g. miscibility of polymer blends, ${ }^{[13]}$ morphology, ${ }^{[14]}$ and distribution of dopant-site sizes $\left.{ }^{[15]}\right)$. We re- 
cently demonstrated the possibility to exploit excimer-forming dyes for the design of stimuli-responsive polymers, which change their emission color upon exposure to a range of stimuli. ${ }^{[16]}$ These materials are produced by incorporating small amounts of excimer-forming sensor dyes into a variety of host polymers. In most cases this can be achieved by creating physical blends of the dye and the host polymer by conventional melt-processing techniques. ${ }^{[17]}$ The approach exploits the excimer-forming properties of chromophores such as cyano-substituted oligo(phenylene vinylene) $\mathrm{s}^{[18]}$ (cyano-OPVs) and further relies on the stimulus-driven self-assembly or dispersion of nano-scale aggregates of these sensor dyes in a range of host polymers (Fig. 1). We have shown that this general concept of stimulus-triggered dye (dis)assembly in polymer matrices allows one to create a broad range of sensor materials, which are useful for the detection of temperature history, ${ }^{[19-23]}$ exposure to chemicals, $[24,25]$ and mechanical deformation, ${ }^{[20,21,26-28]}$ as well as more complex combinations of stimuli, such as those encountered in shape-memory materials (Fig. 2). [29] Cyano-OPVs appear to be ideal for these sensing schemes: these dyes are readily synthesized through the Knoevenagel reaction of phenyl acetonitriles with terephthaldicarboxyaldehydes, their optical properties and (in)solubility in polymer hosts are easily changed by variation of peripheral groups, and their high thermal stability allows for melt processing with thermoplastic polymers at temperatures of up to $300{ }^{\circ} \mathrm{C}$. Other groups, however, have successfully adapted the concept to a range of other dyes including cyano-containing poly(phenylene ethynylenes), ${ }^{[30]}$ perylenes, ${ }^{[31]} \mathrm{CdS}$ nanoparticles, ${ }^{[32]}$ and bis(benzoxazolyl)stilbene. [33]

The temperature and chemical exposure sensors based on such polymer/ dye blends operate by kinetically trapping a thermodynamically unstable molecular mixture of the components by rapidly cooling a hot (and at this temperature miscible) mixture below its glass transition temperature $\left(T_{\mathrm{g}}\right)^{[19-25]}$ If the material is subsequently heated above $T_{\mathrm{g}}$, the system becomes sufficiently mobile so that it can equilibrate, resulting in aggregation of the dye molecules and the formation of excimers (Fig. 2b). This approach has been applied to a range of host polymers including polycarbonate, poly(methyl methacrylate) and acrylic copolymers, polycycloolefins, polyesters, and others, yielding time-temperature indicating materials that exhibit a pronounced fluorescence color change above their respective $T_{\mathrm{g}} \mathrm{s}$. The kinetics follow a predictable, Arrhenius-type behavior: above $T_{\text {, }}$, the aggregation rate increases exponential-

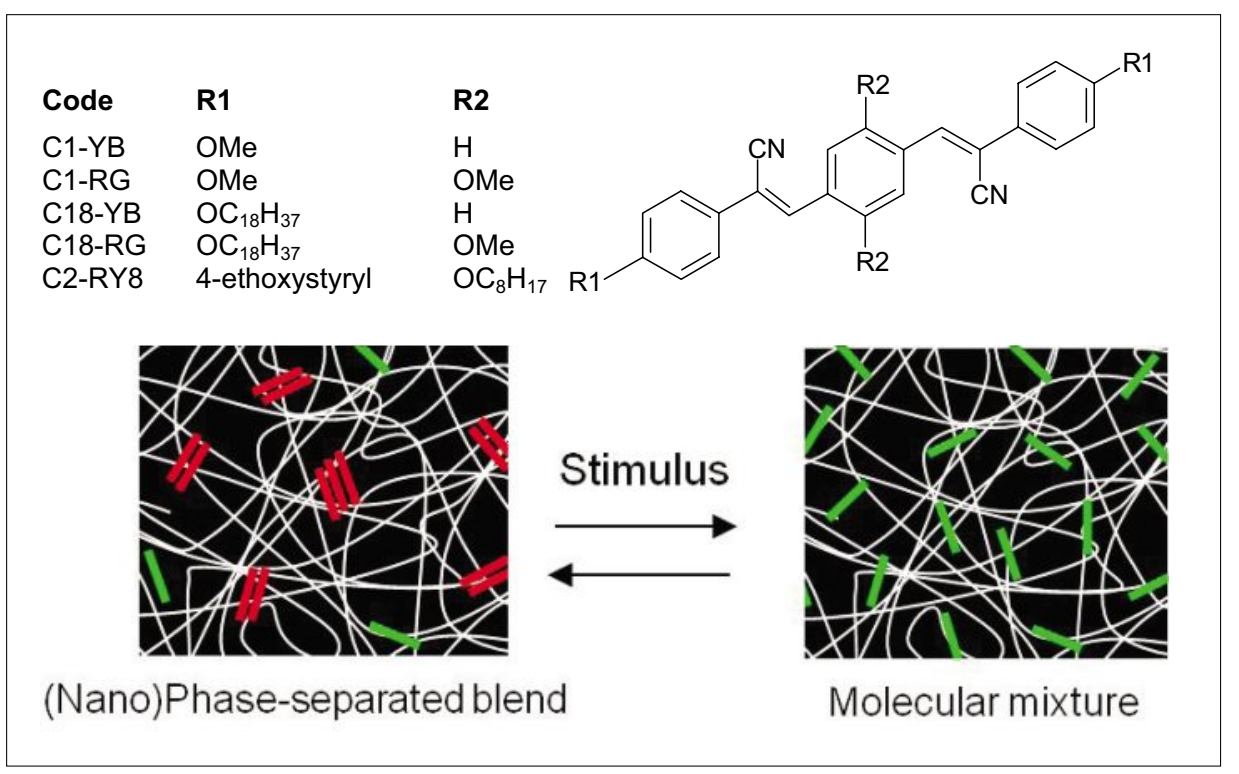

Fig. 1. Chemical structure of fluorescent, excimer-forming, cyano-substituted oligo(phenylene vinylene)s (cyano-OPVs) used as sensors in stimuli-responsive 'chameleon' polymers and schematic representation of the sensing mechanism, which relies on stimulus-driven selfassembly or dispersion of nano-scale aggregates of these sensor dyes in a host polymer.

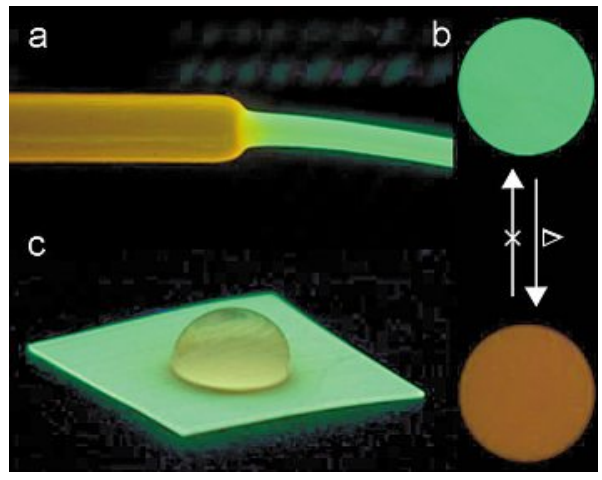

Fig. 2. Pictures of stimuli-responsive cyano-OPV/polymer blends exposed to (a) mechanical deformation, (b) temperatures above the polymer's $T_{g}$, and (c) water.

ly with temperature. ${ }^{[19-25]}$ The aggregation rate increases with dye concentration and decreases with molecular size of the dye in a predictive manner. Thus, three readily changeable design parameters (polymer $T_{\mathrm{g}}$, dye content, dye size) allow one to control the kinetics of the color change over orders of magnitude and broad temperature ranges in a most facile way.

We have also applied the sensing approach to create new shape memory polymers (SMPs) with built-in temperature sensing capabilities. ${ }^{[8]}$ For example, one series of materials was prepared by incorporating 1,4 -bis $(\alpha$-cyano-4octadecyloxystyryl)-2,5-dimethoxybenzene (C18-RG, Fig. 1) into a cross-linked poly(cyclooctene) (PCO) matrix via guestdiffusion. The dye concentration was chosen to allow for self-assembly of the dye upon drying, resulting in the formation of excimers. Exposure of these phase-separat- ed blends to temperatures above the melting point $\left(T_{\mathrm{m}}\right)$ of the PCO leads to dissolution of the dye molecules, and therefore causes a pronounced change of their absorption and fluorescence color. In this case, the optical changes are reversible; i.e. the aggregate absorption and emission are restored upon cooling below $T_{\mathrm{m}}$. The color is dictated by the phase behavior and is independent of the mechanical state of the SMP. Thus the effect allows one to monitor reaching of the set/ release temperature of the polymer.

For the exploitation of the approach to create humidity sensors, a hygroscopic host polymer is chosen, which has a $T$ that is above the desired working temperature. ${ }^{24]}$ Moisture serves to plasticize the matrix, for example a polyamide, thus lowering $T_{\mathrm{g}}$ and providing the mobility to facilitate the aggregation process. The same concept can be applied to detect other chemical stimuli. ${ }^{[25]}$ For example, cyano-OPVs were incorporated into a cross-linked epoxy resin by reacting monomer/cross-linker/dye mixtures at $180-200{ }^{\circ} \mathrm{C}$ and quenching the cured polymer to below $T$. The exposure of the materials to selected chemical stimuli $-e . g$. water, acid, base and several organic compounds - causes plasticization of the polymer matrix and leads to irreversible aggregation of dye molecules, concomitant with the pronounced fluorescence and absorption color change. Also in this case, the response is well described by standard kinetic models and can be controlled via the chemical structure and crosslink density of the resin and the structure and content of the dye.

The mechanically responsive systems based on this framework rely on the inverse mechanism, namely the dissolution of na- 
no-scale dye aggregates upon deformation of the material (Fig. 2a). Systematically investigating several model systems, including polyolefins, ${ }^{20,26-28]}$ polyurethanes.[17] polyesters, $[17,20,21]$ and fluoropolymers, we explored how the nature of the polymer, dye concentration and solubility in the host polymer, dye aggregate size, and effectiveness of the dye aggregate break-up influence the mechanochromic response of such materials. The dye concentration in the material must be sufficiently high to cause the aggregation of dye molecules and lead to the formation of static excimers upon cooling the blends from the homogeneous melts. The semicrystalline polymers studied display an appreciable amorphous fraction, in which the dye resides, and which have a $T_{\mathrm{g}}$ below ambient. This provides for adequate translational mobility of the dye molecules in the matrix polymer after processing, so that aggregation is possible upon cooling. Appropriate (in) solubility of the dyes in a particular matrix polymer can be tailored by changing

$\boldsymbol{C}$ the nature of the substituents attached to

u the dye core, e.g. the length of (aliphatic) peripheral groups. ${ }^{[21]}$ Using a series of polyethylenes (PEs) of different crystallinity, and the two dyes 1,4-bis $(\alpha$-cyano4-methoxystyryl)-2,5-dimethoxybenzene (C1-RG) and C18-RG (Fig. 1) we demonstrated that the formation of small dye aggregates upon cooling the blends from the homogeneous melts is important for efficient mechanochromic systems, since large-scale phase separation limits or prevents the break-up of the dye aggregates upon deformation. ${ }^{[28]}$ The rate at which C1-RG aggregates, the aggregate size, and the extent of aggregation were found to decrease with increasing polymer crystallinity. ${ }^{[28]}$ This observation is in agreement with the well-established decrease of the fractional free volume of the non-crystalline component of PE with increasing crystallinity and reflects a decrease of the dye's translational mobility. While in linear lowdensity polyethylene of moderately high density $\left(0.94 \mathrm{~g} \mathrm{~cm}^{-3}\right)$ the aggregation of C1-RG can (at room temperature) occur over several months, ${ }^{[27]}$ dye aggregation and excimer formation was found to be virtually instantaneous in a range of different PE grades comprising C18-RG. ${ }^{[28]}$ Together with the fact that in similarly processed PE samples C18-RG formed much smaller aggregates than $\mathrm{C} 1-\mathrm{RG}$, it appears that the nucleation of $\mathrm{C} 18-\mathrm{RG}$ is much faster than that of $\mathrm{C} 1-\mathrm{RG}$, leading to the rapid growth of smaller aggregates, which are more easily dispersed upon deformation than those of C1-RG and result in a more substantial fluorescence color change (Fig. 2a). ${ }^{[28]}$ In situ opto-mechanical experiments have shown that the fluorescence color change of blends upon deformation matches nicely

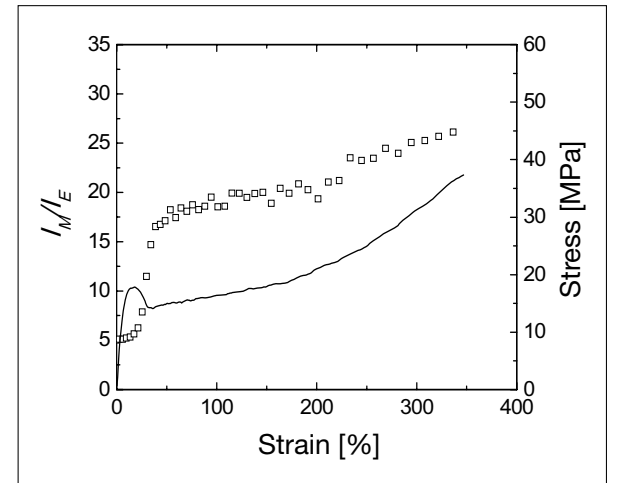

Fig. 3. Plot of fluorescence color (expressed as ratio of monomer to excimer emission intensity, $I_{M} / I_{E}$, measured at 540 and $650 \mathrm{~nm}$, squares), and tensile stress (line) as a function of strain for a blend of a linear low-density polyethylene and $0.1 \% \mathrm{w} / \mathrm{w} \mathrm{C18-RG.}{ }^{[28]}$

with the shape of the stress-strain profiles for the samples (Fig. 3). Blend films based on a wide range of polyethylene matrices exhibit a steep increase in color change upon yielding, an only moderate increase during neck propagation, and a slightly steeper increase during strain hardening. It was also shown that the magnitude of the fluorescence color change, and therewith the extent of aggregate break-up increases with decreasing strain rate. Investigation of the effect of polymer crystallinity on the mechanochromic response of $\mathrm{PE} /$ C18-RG blends revealed a larger extent of color change upon deformation for the higher crystallinity PEs. From a mechanistic aspect, it appears that the ability of the polymer host to disperse dye aggregates upon deformation is primarily related to the plastic deformation process of the PE crystallites. ${ }^{[28]}$ These findings are consistent with the mechanochromic response of several polyesters and fluoropolymers that have also been investigated. [17,21]

Related work by our group focused on the extension of the general sensing approach to dye systems which show optical absorption changes upon self-assembly, due to charge-transfer interactions or conformation changes. ${ }^{[20]}$ Interestingly, some cyano-OPVs, including C2-RY8 (Fig. 1) and C18-RG display such 'aggregachromic' behavior, while others (e.g. C1-YB, C1-RG) do not. This difference demonstrates that the optical changes that result from self-assembly of $\pi$-conjugated chromophores are often difficult to predict, due to the complex intermolecular interactions and the intimate relation between molecular conformation and aggregate morphology and optical properties.

In summary, the introduction of chromophores that change their optical properties upon self-assembly into polymers has resulted in a range of stimuli-responsive polymer systems with interesting sens- ing capabilities. The possibility to control the phase behavior and supramolecular architecture of these systems, using both thermodynamic and kinetic tools, is key to minutely tailor their properties.

\section{Noncoherent Low-Power Upconversion in Solid Polymers}

The ability to control the interactions among - in this case different - chromophore molecules within a polymer matrix, is also key for the realization of solid polymer materials that enable the optical upconversion of low-power, non-coherent continuous-wave excitation sources under exploitation of sequential, highly-allowed one photon absorption processes (as opposed to nonlinear optical processes). This scheme was first introduced by Parker and Hatchard in organic multi-chromophore systems, which comprise a triplet sensitizer and an emitter; $[34,35]$ light is absorbed by the triplet sensitizer, whose first singlet excited state is converted into a triplet upon intersystem crossing. Energy transfer to an emitter and triplet-triplet annihilation eventually causes singlet fluorescence by the emitter. The original systems contained triplet sensitizers, which exhibited low intersystem crossing yields and limited the upconversion efficiency. Since the original work in this area, the dye systems have been significantly improved by utilizing various heavy metal-containing sensitizers. Examples range from chromophores that exhibit metal-to-ligand charge transfer, such as $\mathrm{Ru}(\mathrm{II})^{[36,37]}$ and $\operatorname{Ir}(\mathrm{III})$ complexes, ${ }^{[38]}$ to chromophores that exhibit low energy $\pi-\pi^{*}$ transitions, such as a wide range of metalloporphyrins. ${ }^{[39]}$ Until recently, however, the sensitized upconversion scheme was only feasible in liquid solutions of the chromophores. In close collaboration with the Castellano group, ${ }^{[36-39]}$ we recently created blends of such chromophores with suitable polymer matrices and reported materials that display noncoherent low-power upconversion in solid polymer films. ${ }^{40,41]}$

With the notion that chromophore diffusion must be possible to allow for the annihilation of two triplets in polymer/dye blends that comprise the chromophores in low concentration $(\sim \mathrm{mM}), \operatorname{Pd}(\mathrm{II})$ octaethylporphyrin (sensitizer, PdOEP) and 9,10-diphenylanthracene (emitter, DPA) were first incorporated into a 1:1 copolymer of ethyleneoxide and epichlorohydrin (EO-EPI), which served as an example of an essentially amorphous rubbery polymer host with a glass transition ( $236 \mathrm{~K})$ below ambient (Fig. 4). The concentrations of the chromophores were kept low $(0.2-0.3 \mathrm{mM}$ PdOEP and 18-20 mM DPA) in order to prevent large-scale phase separation. Se- 
lective excitation of the PdOEP with green light at $544 \mathrm{~nm}$ under ambient conditions results in sensitized DPA triplet formation by way of intersystem crossing and diffusive energy transfer. Triplet-triplet annihilation (TTA) of ${ }^{3} \mathrm{DPA}^{*}$ molecules eventually causes anti-Stokes delayed blue singlet fluorescence centered at $445 \mathrm{~nm}$. Green-to-blue upconversion facilitated by this chromophore pair in a polymer matrix was clearly visible by the unassisted eye in a well illuminated room upon excitation with a $532 \mathrm{~nm}, 5 \mathrm{~mW}$ laser pointer as the light source (Fig. 5).

The quadratic incident power dependence as well as the static and timeresolved emission data reported for this material support the conclusion that the singlet DPA fluorescence observed is indeed the result of the proposed sensitized TTA-based mechanism (Fig. 6). ${ }^{40,41]}$ The fact that the translational mobility of the chromophores in the matrix polymer is essential was demonstrated by the finding that upconversion was completely suppressed at $77 \mathrm{~K},{ }^{[40]}$ i.e. well below the glass transition temperature of EO-EPI. This is consistent with the inhibition of chromophore diffusion in the glassy state, preventing the necessary bimolecular interactions among sensitizer and acceptor/annihilator (required for energy transfer) and among two acceptor/annihilator molecules (required for TTA). In a subsequent systematic study, which involved the investigation of four different host polymers (in addition to EO-EPI, three different polyurethanes were studied) over a range of temperatures, the mechanism of low-power upconversion in rubbery and glassy polymer blends was probed in more detail.[41] It was shown that in all systems the upconverted DPA emission intensity increases with increasing temperature, but is suppressed below the polymers' respective $T_{g}$.

In summary, the simple incorporation of judiciously composed chromophore cocktails, whose collective optical properties rely on carefully matched electronic states, into polymers has resulted a range of polymer systems which display lowenergy optical upconversion. The process relies on an energy transfer scheme that requires dynamic interactions among the chromophores, which in turn are enabled by the specific characteristics of the chosen polymer host.

\section{Mechanically Adaptive Polymer Nanocomposites}

Polymers which change their mechanical properties 'on command', i.e. upon exposure to a pre-defined stimulus in a highly selective and reversible manner, are attractive for countless technologically relevant

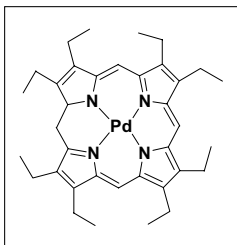

(a)
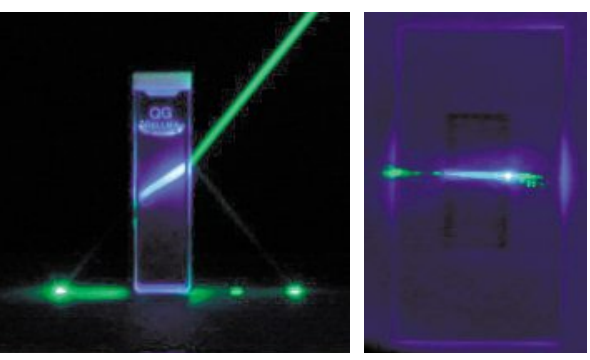

Fig. 5. Pictures of a PdOEP/DPA solution (left) and a PdOEP/DPA doped EO-EPI film (right) under excitation with a $532 \mathrm{~nm}, 5 \mathrm{~mW}$ laser pointer.
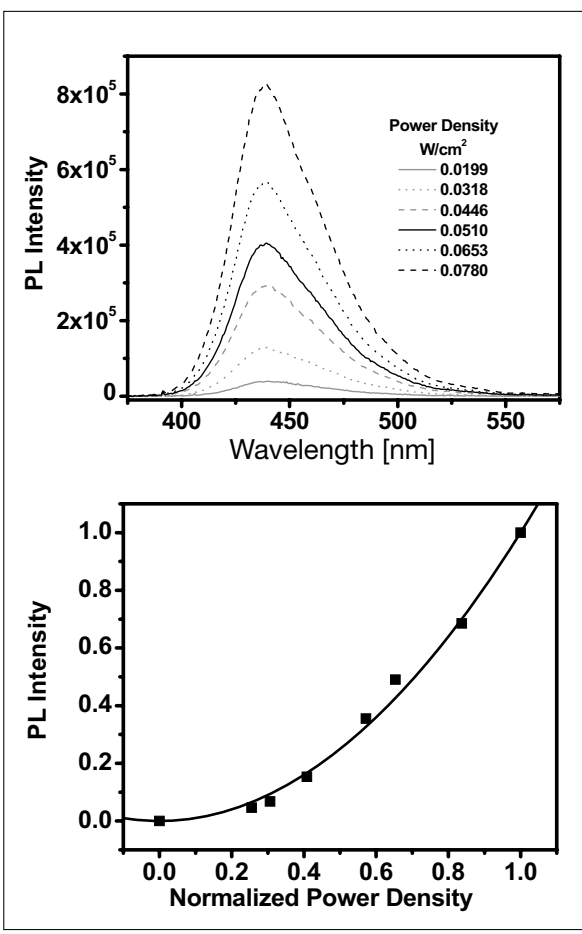

Fig. 6. (a) Upconverted emission intensity profiles of a PdOEP/DPA EO-EPI film at 360 $\mathrm{K}$ in a vacuum operated cryostat following selective excitation of PdOEP at $544 \mathrm{~nm}$ filtered through a $515 \mathrm{~nm}$ long pass filter, 2 $\mathrm{mJ} /$ pulse. (b) Normalized integrated emission intensity from part (a) plotted as a function of the normalized incident light power. The black line in (b) represents the best quadratic fit $\left(\mathrm{x}^{2}\right)$ to the data. The figure is based on data from ref. [41].

applications.[9] Shape-memory polymers, which have the ability to return from a deformed state to their original shape through a temperature increase (or exposure to other stimuli that cause a temperature increase) represent a design approach that is

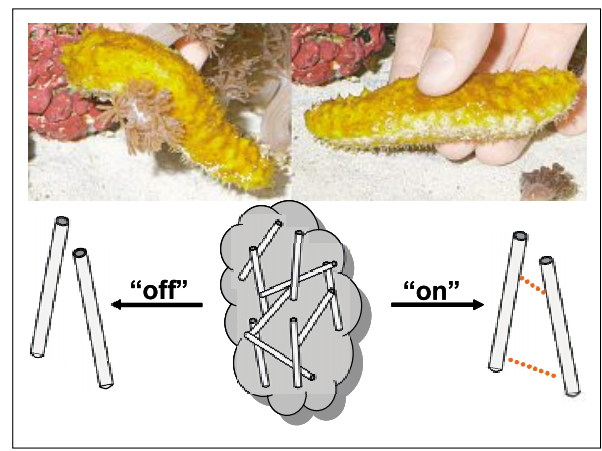

Fig. 7. Pictures of a sea cucumber in soft and stiff state and schematic of the switching mechanism in this model and the proposed biomimetic nanocomposites. The stress transfer among rigid, percolating nanofibers, and therewith the overall stiffness, is controlled by a stimulus. The figure is reproduced from ref. [55].

currently receiving much attention. ${ }^{[42-45]}$ Other classes of widely investigated mechanically adaptable materials include temperature- and chemo-responsive polymer (hydro)gels and networks, ${ }^{46,47]}$ photoresponsive gels, ${ }^{[48]}$ liquid-crystalline elastomers, ${ }^{[49]}$ electro-rheological fluids and gels, ${ }^{[50]}$ as well as materials that undergo dimensional changes upon stimulation, for example electrostrictive materials. ${ }^{[51]}$ While the mechanical changes of these materials can be quite dramatic - some exhibit viscosity/modulus changes of several orders of magnitude - the large majority of these mechano-responsive materials exhibit a very low modulus. ${ }^{[52]}$ While their property profiles are ideal for applications such as drug delivery[53] and cell culturing, ${ }^{[54]}$ examples of much stiffer materials that exhibit such morphing mechanical behavior are limited.

We recently introduced a family of novel bio-inspired polymer nanocomposites with stimulus-responsive mechanical properties, in which a chemical stimulus causes a significant and reversible stiffness change. ${ }^{55]}$ The materials design mimics the structural concepts at play in the dermis of sea cucumbers (Fig. 7). ${ }^{[56]}$ Like other echinoderms, these creatures have the ability to rapidly and reversibly alter the stiffness of their inner dermis when threatened. ${ }^{[57]} \mathrm{Re}$ cent studies on the dermis of these invertebrates provided evidence that this dynamic mechanical behavior is achieved through a nanocomposite architecture, in which 
rigid collagen fibrils reinforce a viscoelastic matrix (Fig. 1). ${ }^{[58]}$ The tissue stiffness is regulated by controlling the stress transfer between adjacent collagen fibrils via transiently established interactions. ${ }^{[59]}$ These are modulated by locally secreted proteins, which switch between rigid and soft states. The dermis of the Cucumaria frondosa and other sea cucumber species thus represents a compelling model of a chemo-responsive material in which a large modulus contrast $(\sim 5$ to $50 \mathrm{MPa})$ is possible.

Intrigued by this capability and with the initial goal of creating new adaptive materials for biomedical applications, we launched an experimental research program that sought to investigate whether artificial nanocomposites can be created that exhibit similar architecture and properties. ${ }^{[60-67]}$ A first series of such materials was created from a rubbery ethylene oxide-epichlorohydrin copolymer (EO-EPI, Fig. 4) into which a rigid cellulose nanofiber network was incorporated (Fig. 8). ${ }^{[55]}$ The EO-EPI matrix displays a low modulus $(\sim 1 \mathrm{MPa}$, depending on monomer ratio) and can acCommodate the uptake of several chemical stimuli. Cellulose nanofibers, isolated from the mantles of sea creatures known as tunicates, were used as the reinforcing fill${ }^{[68]}$ These 'whiskers' exhibit high stiffness (tensile modulus $\sim 130 \mathrm{GPa}$ ) and dimensions at the nanometer scale $(\sim 25 \mathrm{~nm}$ $\times 2.2 \mu \mathrm{m})$. Similar nanofibers can be isolated from a range of biomaterials, including wood and cotton. ${ }^{[68]}$ Good dispersion during processing can be achieved when - whisker self-interactions are 'switched off' by competitive binding with a hydrogenbond-forming solvent.[61,63,64] Upon solvent evaporation the interactions among the whiskers are 'switched on' and they assemble into a percolating network. This architecture and strong interactions among the whiskers maximize stress transfer and

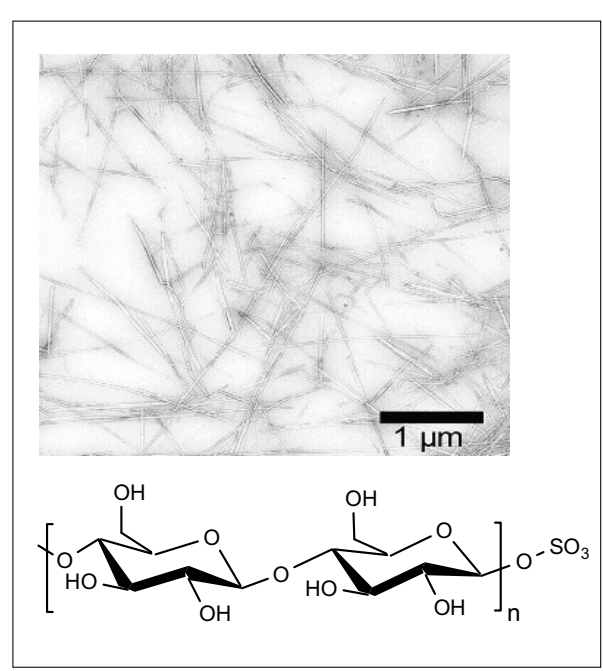

Fig. 8. Transmission electron microscope image of cellulose whiskers (top) and chemical structure of cellulose (bottom).

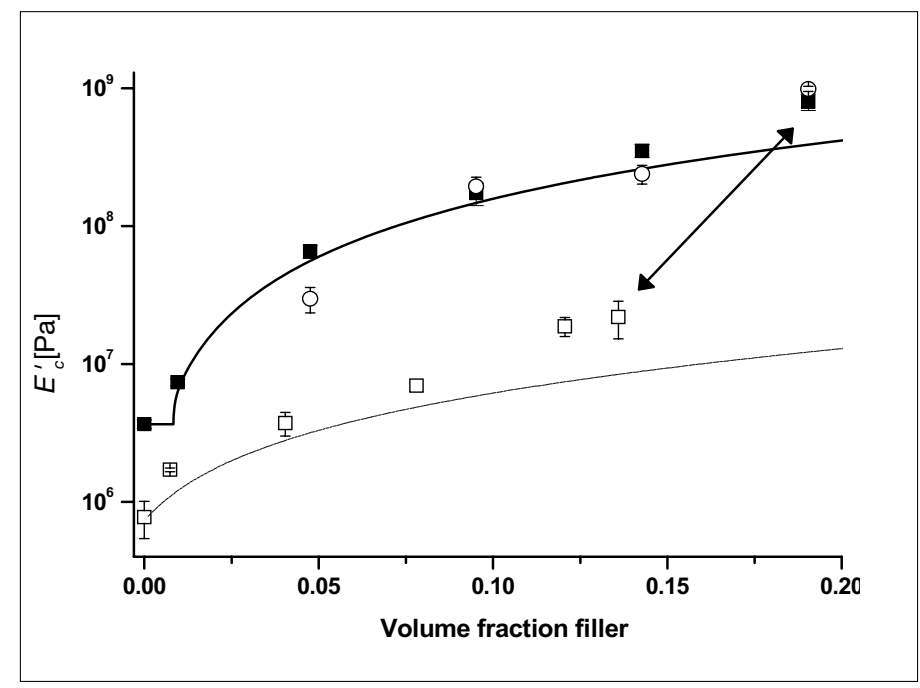

Fig. 9. Tensile storage moduli $E_{C}^{\prime}$ of EO-EPI/cellulose whisker nanocomposites. The materials were dry (घ), water-swollen ( $\square$ ), and redried (०). Lines represent values predicted by the percolation and HalpinKardos models. The arrow indicates changes in modulus and volume fraction of whiskers resulting from aqueous swelling of one selected sample (19\% v/v whiskers). The figure is reproduced from ref. [55].

therewith the overall modulus of polymers which comprise such whisker networks. We demonstrated that the incorporation of percolating networks of cellulose whiskers into an EO-EPI matrix affords nanocomposites in which the modulus can be reversibly changed through the addition or removal of water, which acts as a chemical regulator and changes the hydrogen bonding among the whiskers within the polymer matrix. ${ }^{[55,69]}$ True to the intended design, the uptake of a small amount of water causes a dramatic stiffness reduction (e.g. the tensile storage modulus $E^{\prime}$ is reduced from 800 to $20 \mathrm{MPa}$ for a composite with $19 \% \mathrm{v} / \mathrm{v}$ whiskers); the original stiffness is restored when the composite is dried (Fig. 9). Control experiments and analyses using mechanical models support the conclusion that the stiffness change is due to the designed mechanism of altered whisker-whisker interactions, rather than alternative effects such as plasticization of the matrix.

The approach has in the meantime been applied to other materials. ${ }^{[55,66,67]}$ For example, we developed cellulose nanocomposites with a poly(vinylacetate) (PVAc) matrix, which display even larger, reversible modulus changes (4.2 GPa to $\sim 5 \mathrm{MPa}$ ) upon exposure to emulated physiological conditions. ${ }^{[55,66,67]}$ These materials display a 'dual' responsive behavior. Upon exposure to physiological conditions the materials undergo a phase transition (water plasticizes the material and lowers the glass transition temperature from above to below physiological temperature); in addition, the reinforcing whisker network is disassembled. One currently considered use of such bio-inspired chemically adap- tive nanocomposites is in biomedical applications, specifically as mechanically adaptive substrates for intracortical microelectrodes.[70,71,72]

The success and generality of the new biomimetic design approach to mechanically adaptive nanocomposites encourage extrapolation and motivate the extension to other robust surface chemistries that have the potential to moderate the efficiency of stress transfer among reinforcing elements. To the extent that one can control the surface chemistry of cellulose nanofibers (and other nano-fillers), a broad variety of stimuli (electrical, optical, receptor ligand, etc.) can be programmed to generate desired responses. Because the percolation threshold can be exploited to create what effectively amounts to a phase transition in which large changes in properties are tied to a relatively small number of interactions, a very pronounced mechanical switching, beyond that obtainable for example from plasticizing a polymer with an additive, is possible.

\section{Conclusions}

In summary, the fabrication of blends and nanocomposites of functional additives with 'inert' matrix polymers is an exceedingly attractive, elegant, and in principle very simple design approach for the creation of functional polymer systems with a broad range of attractive properties. It is important to note, however, that the approach usually requires more than simply mixing the components: in all cases discussed here, the matrix polymer plays a very important role and is more than a 
passive binder. Moreover, the assembly of very specific morphologies is often the key to create materials with properties that are absent in the individual components.

\section{Acknowledgements}

I have been privileged to be able to work with many outstanding and researchers in and outside my group. The here-summarized research would not have been possible without the help of J. Capadona, F. Castellano, T. Chung, B. Crenshaw, R. Islangulov, J. Lott, M. Kinami, J. Kunzelman, C. Löwe, P. Mather, S. Rowan, D. Schiraldi, L. Tang, K. Shanmuganathan, R. Simha, C. Sing, T. Singh-Rachford, D. Tyler, and $\mathrm{O}$. van den Berg and without the financial support from 3M, Alcoa Inc., Bayer MaterialScience, DuPont, Hayes Fund, Kimberly Clark Co., L. Stokes Cleveland VAMC Advanced Platform Technology Center, NIH (R21NS053798-01), NSF (DMI-0428208, DMR-0423914), PRF (38525-AC7), Schlumberger, and Toyobo. I also would like to thank Markus Geuss for proofreading the manuscript and Joe Lott for help with the figures.

Received: September 25, 2009

[1] a) M. Eglin, A. Montali, A. R. A. Palmans, T. Tervoort, P. Smith, C. Weder, J. Mater. Chem 1999, 9, 2221; b) C. Kocher, P. Smith, C. Weder, J.Mater. Chem. 2002, 12, 2620.

[2] R. Tangirala, E. Baer, A. Hiltner, C. Weder, $A d v$. Funct. Mater. 2004, 14, 595.

[3] C. Schmitz, P. Pösch, M. Thelakkat, H.-W. Schmidt, A. Montali, K. Feldman, P. Smith, C. Weder, Adv. Funct. Mater. 2001, 11, 41.

[4] M. Burnworth, J. D. Mendez, M. Schroeter, S J. Rowan, C. Weder, Macromolecules 2008, 41, 2157.

[5] K. D. Singer, J. Lott, T. Kazmierczak, H. Song, Y. Wu, J. Andrews, E. Baer, A. Hiltner, C Weder, Opt. Express. 2008, 16, 10358.

[6] M. Burnworth, S. J. Rowan, C. Weder, Chem. Eur. J. 2007, 13, 7828.

[7] D. Knapton, M. Burnworth, S. J. Rowan, C. Weder, Angew. Chem. Int. Ed. 2006, 45, 5825.

[8] J. Kunzelman, C. Chung, T. M. Mather, C. Weder, J. Mater. Chem. 2008, 18, 1082.

[9] 'Intelligent Materials', Eds. M. Shahinpoor, H.-J. Schneider, CRC Press, 2004

[10] a) T. Förster, K. Kasper, Z. Physik. Chem. NF 1954, 1, 275; b) T. Förster, K. Kasper, $Z$ Elektrochem. Angew. Physik. Chem. 1955, 59 , 976.

[11] The term 'monomer' is used to describe emission from single-molecule excited states, as opposed to excimers.

[12] a) P. D. Fitzgibbon, C. W. Frank, Macromolecules 1981, 14, 1650; b) N. J. Turro, K. S. Arora, Polymer 1986, 27, 783 c) H. T. Oyama, W. T. Tang, C. W. Frank, Macromolecules 1987, 20, 474; d) Y. C. Wang, H. Morawetz, Macromolecules 1989, 22, 164.

[13] a) S. N. Semerak, C. W. Frank, Macromolecules 1981, 14, 443; b) M. A. Gashgari, C. W. Frank, Macromolecules 1981, 14, 1558; c) R. Gelles, C. W. Frank, Macromolecules 1982, 15, 1486 d) S. N. Semerak, C. W. Frank, Macromolecules 1984, 17, 1148

[14] a) O. E. Zimerman, R. G. Weiss, J. Phys. Chem. A 1998, 102, 5364; b) M. R. Vigil, J. Bravo, J. Baselga, S. B. Yamaki, T. D. Z. Atvars, Curr. Org. Chem. 2003, 7, 197.

[15] J. Naciri, R. G. Weiss, Macromolecules 1989, 22, 3928.

[16] C. Löwe, C. Weder, 'Photoluminescent Polymer Blends and Uses Therefore', US 7,223,988, 2007, Case Western Reserve University.
[17] For examples of covalent integration of excimer-based sensors into polymers see: a) B. Crenshaw, C. Weder, Macromolecules 2006, 39, 9581; b) J. Kunzelman, M. Gupta, B. R. Crenshaw, D. A. Schiraldi, C. Weder, Macromol. Mater. Eng. 2009, 294, 244.

[18] M. Irie, Chem. Rev. 2000, 100, 1685.

[19] B. R. Crenshaw, C. Weder, Adv. Mater. 2005 , $17,1471$.

[20] J. Kunzelman, B. R. Crenshaw, M. Kinami, C. Weder, Macromol. Rapid Comm. 2006, 27, 1981.

[21] M. Kinami, B. R. Crenshaw, C. Weder, Chem. Mater. 2006, 18, 946.

[22] B. R. Crenshaw, J. Kunzelman, C. E. Sing, C. Ander, C. Weder, Macromol. Chem. Phys. 2007, 208,572

[23] C. E. Sing, J. Kunzelman, C. Weder, J. Mater. Chem. 2009, 19, 104.

[24] J. Kunzelman, B. R. Crenshaw, C. Weder, J. Mater. Chem. 2007, 17, 2989.

[25] L. Tang, J. Whalen, G. Schutte, C. Weder, ACS Appl. Mater. Interf. 2009, 1, 688.

[26] C. Löwe, C. Weder, Adv. Mater. 2002, 14, 1625.

[27] B. R. Crenshaw, C. Weder, Chem. Mater. 2003, $15,4717$.

[28] B. R. Crenshaw, M. Burnworth, D. Khariwala, A. Hiltner, P. T. Mather, R. Simha, C. Weder, Macromolecules 2007, 40, 2400.

[29] J. Kunzelman, T. Chung, P. T. Mather, C. Weder, J. Mater. Chem. 2008, 18, 1082 .

[30] A. Pucci, T. Biver, G. Ruggeri, L. I. Meza, Y. Pang, Polymer 2005, 46, 11198 .

[31] F. Donati, A. Pucci, C. Cappelli, B. Mennucci, G. Ruggeri, J. Phys. Chem. B 2008, 112, 3668

[32] A. Pucci, M. Boccia, F. Galembeck, C. Leite, N. Tirelli, G. Ruggeri, React. Funct. Polym. 2008, 68,1144

[33] A. Pucci, F. Di Cuia, F. Signori, G. Ruggeri, $J$. Mater. Chem. 2007, 17, 783

[34] C. A. Parker, C. G. Hatchard, Proc. R. Chem. Soc., London 1962, 386.

[35] C. A. Parker, Adv. Photochem. 1964, 2, 305.

[36] R. R. Islangulov, D. V. Kozlov, F. N. Castellano, Chem. Commun. 2005, 3776.

[37] R. R. Islangulov, F. N. Castellano, Angew. Chem. Int. Ed. 2006, 45, 5957.

[38] Z. Wei, F. N. Castellano, J.Phys. Chem. A 2006 110,11440

[39] a) S. Baluschev, T. Miteva, V. Yakutkin, G. Nelles, A. Yasuda, G. Wegner, Phys. Rev. Lett. 2006, 97, 143903(1); b) S. Baluschev, J. Jacob, Y. S. Avlasevich, P. E. Keivanidis, T. Miteva, A. Yasuda, G. Nelles, A. C. Grimsdale, K. Muellen, G. Wegner, ChemPhysChem 2005, 6,1250 ; c) S. Baluschev, P. E. Keivanidis, G. Wegner, J. Jacob, A. C. Grimsdale, K. Muellen, T. Miteva, A. Yasuda, G. Nelles, Appl. Phys. Lett. 2005, 86, 061904/1; d) S. Baluschev, V. Yakutkin, T. Miteva, Y. Avlasevich, S. Chernov, S. Aleshchenkov, G. Nelles, A. Cheprakov, A. Yasuda, K. Muellen, G. Wegner, Angew. Chem. Int. Ed. 2007, 46, 7693; e) S. Baluschev, V. Yakutkin, G. Wegner, B. Minch, T. Miteva, G. Nelles, A. Yasuda, J. Appl. Phys. 2007, 101, 023101/1; f) T. N. Singh-Rachford, F. N. Castellano, J. Phys. Chem. A 2008, 112, 3550; g) T. N. Singh-Rachford, A. Haefele, R. Ziessel, F. N. Castellano, J. Am. Chem. Soc. 2008, 130, 16164; h) T. N. Singh-Rachford, Inorg. Chem. 2009, 48, 2541

[40] R. R. Islangulov, J. Lott, C. Weder, F. N. Castellano, J. Am. Chem. Soc. 2007, 129, 12652.

[41] T. N. Singh-Rachford, J. Lott, C. Weder, F. N. Castellano, J. Am. Chem. Soc. 2009, 131, 12007.

[42] A. Lendlein, S. Kelch, Angew. Chem. Int. Ed. $\mathbf{2 0 0 2}, 41,2034$

[43] A. Lendlein, R. Langer, Science 2002, 296, 1673.

[44] A. Lendlein, H. Jiang, O. Juenger, R. Langer, Nature 2005, 434, 879

[45] C. Liu, H. Qin, P. T. Mather, J. Mater. Chem.
2007, 17,1543

[46] C. de las Heras Alarcón, S. Pennadam, C. Alexander, Chem. Soc. Rev. 2005, 34, 276.

[47] D. M. Loveless, S. L. Jeon, S. L. Craig, J. Mater. Chem. 2007, 17, 56.

[48] T. Suzuki, S. Shinkai, K. Sada, Adv. Mater 2006, 18, 1043.

[49] M. Warner, E. M. Terentjev, 'Liquid Crystal Elastomers', Clarendon Press, Oxford, 2003.

[50] K. Minagawa, K. Koyama, Curr. Org. Chem. 2005, 16, 1643.

[51] R. Pelrine, R. Kornbluh, Q. B. Pei, J. Joseph, Science 2000, 287, 836.

[52] R. Yoshida, Curr. Org. Chem. 2005, 16, 1617.

[53] D. Needham, M. W. Dewhirst, Adv. Drug Deliv. Rev. 2001, 53, 285.

[54] T. Shimuzu, M. Yamato, A. Kikuchi, T. T. Okano, Tissue Engineering 2001, 7, 141

[55] J. R. Capadona, K. Shanmuganathan, D. Tyler S. J. Rowan, C. Weder, Science 2008, 319, 1370.

[56] 'Echinoderms', Eds. T. Heinzeller, J. Nebelsick, Taylor \& Francis Group, London, 2004

[57] T. Motokawa, Compl. Biochem. Physiol. 1996, 5,61 .

[58] J. A. Trotter, J. Tipper, G. Lyons-Levy, K Chino, A. H. Heuer, Z. Liu, M. Mrksich, C. Hodneland, W. Shannon Dillmore, T. J. Koob, M. M. Koob-Emunds, K. Kadler, D. Holmes, Biochem. Soc. Trans. 2000, 28, 357.

[59] G. K. Szulgit, R. E. Shadwick, J. Exp. Biol. 2000, 203, 1539

[60] M. Schroers, A. Kokil, C. Weder, J. Appl. Polym. Sci. 2004, 93, 2883

[61] O. van den Berg, J. R. Capadona, C. Weder, Biomacromolecules 2007, 8, 1353.

[62] O. van den Berg, M. Schroeter, J. R. Capadona, C. Weder, J. Mater. Chem. 2007, 17, 2746.

[63] J. R. Capadona, O. van den Berg, L. Capadona, D. Tyler, S. J. Rowan, C. Weder, Nature Nanotechnology 2007, 2, 765.

[64] J. R. Capadona, K. Shanmuganathan, S Trittschuh, S. Seidel, S. J. Rowan, C. Weder, Biomacromolecules 2009, 10, 712 .

[65] M. D. Gawryla, O. van den Berg, C. Weder, D. A. Schiraldi, J. Mater. Chem. 2009, 19, 2118.

[66] K. Shanmuganathan, J. R. Capadona, S. J. Rowan, C. Weder, Progr. Polym. Sci., in press.

[67] K. Shanmuganathan, J. R. Capadona, S. J. Rowan, C. Weder, J. Mater. Chem., in press.

[68] M. De Souza Lima, R. Borsali, Macromol. Rapid Commun. 2004, 25, 771 .

[69] a) R. V. Bellamkonda, Nature Materials 2008 7, 347; b) S. L. Craig, Angew. Chem. Int. Ed. $2008,47,8776$.

[70] D. M. Taylor, S. I. H. Tillery, A. B. Schwartz, Science 2002, 296, 1829.

[71] A. B. Schwartz, Annu. Rev. Neurosci. 2004, 27, 487.

[72] A. Hess, J. Dunning, J. Harris, J. R. Capadona, K. Shanmuganathan, S. Rowan, C. Weder, D. Tyler, C. A. Zorman, IEEE Proceedings, Transducers 2009, submitted. 